\title{
Growth Factor Activity of Endothelin-1 in Primary Astrocytes Mediated by Adhesion-Dependent and -Independent Pathways
}

\author{
Sylvie Cazaubon, ${ }^{1}$ Nathalie Chaverot, ${ }^{1}$ Ignacio A. Romero, ${ }^{1}$ Jean-Antoine Girault, ${ }^{2}$ Peter Adamson, ${ }^{3}$ \\ A. Donny Strosberg, ${ }^{1}$ and Pierre-Olivier Couraud ${ }^{1}$ \\ ${ }^{1}$ Centre National de la Recherche Scientifique UPR 0415, Institut Cochin de Génétique Moléculaire, 75014 Paris, France, \\ 2/nstitut National de la Santé et de la Recherche Médicale U114, Collège de France, 75005 Paris, France, and ${ }^{3 / n s t i t u t e ~}$ \\ of Ophthalmology, University College London, London EC1V 9EL, United Kingdom
}

Endothelin-1 (ET-1) has been shown to induce DNA synthesis in primary astrocytes by stimulating the extracellular signalregulated kinase (ERK) pathway. To clarify the mechanisms responsible for the anchorage-dependent growth of astrocytes, the relationships between cell adhesion and ERK activation were investigated. Here it is reported that ET-1 promotes the formation of stress fibers and focal adhesions and the tyrosine phosphorylation of focal adhesion kinase (FAK) and paxillin, as well as Src activation and association of phosphorylated FAK with Grb2. Pretreatment of astrocytes with cytochalasin D or C3-transferase, which inhibits actin polymerization or Rho activity, respectively, prevented the activation/phosphorylation of Src, FAK, and paxillin after ET-1 stimulation; by contrast, the ERK pathway was not significantly affected. This differential activation of FAK/Src and ERK pathways was also observed with astrocytes 10 and 60 min after replating on poly-L- ornithine-precoated dishes. Collectively, these findings indicate that activation of FAK and Src is dependent on actin cytoskeleton integrity, Rho activation, and adhesion to extracellular matrix, whereas ERK activation is independent of these intracellular events and seems to correlate with activation of the newly identified protein tyrosine kinase PYK2. Induction of DNA synthesis by ET-1, however, was reduced dramatically in astrocytes pretreated with either cytochalasin D or C3-transferase. This study provides a demonstration of Rho- and adhesiondependent activation of FAK/Src, which collaborates with adhesion-independent activation of PYK2/ERK for DNA synthesis in ET-1-stimulated astrocytes.

Key words: endothelin-1; growth factor; primary astrocyte; cell adhesion; stress fibers; focal adhesion kinase; extracellular signal-regulated kinase
Endothelin-1 (ET-1) has been implicated in a wide variety of physiological functions associated with the cardiovascular, endocrine, pulmonary, renal, and nervous systems. Brain microvascular endothelial cells, which constitute the blood-brain barrier, have been shown to produce ET-1 (Durieu-Trautmann et al., 1993). This peptide modulates the functions of the surrounding astrocytes, stimulating DNA synthesis and proliferation and secretion of neurotrophic factors (MacCumber et al., 1990; Couraud et al., 1991; Ladenheim et al., 1993). These observations strongly suggest that ET-1 can act as a growth factor for astrocytes, regulating biological processes such as proliferation during brain development or injury.

In primary astrocytes, responses to ET- 1 are mediated by $\mathrm{ET}_{\mathrm{B}}$ receptors, which belong to the superfamily of receptors containing seven transmembrane domains and are coupled to heterotrimeric G-proteins (Sakurai et al., 1990). In previous studies, it has been shown that stimulation of $\mathrm{ET}_{\mathrm{B}}$ receptors can induce the tyrosine phosphorylation of several cellular proteins, including extracellular signal-regulated kinase (ERK) (Cazaubon et al.,

Received Jan. 7, 1997; revised May 19, 1997; accepted May 29, 1997.

This work was supported by the Centre National de la Recherche Scientifique, the Institut National de la Santé et de la Recherche Médicale, the Association pour le Développement de la Recherche sur le Cancer, the Ligue Nationale Française contre le Cancer, the Université of Paris, and the Ministère de la Recherche et de l'Enseignement Supérieur. We thank Dr. A. Koman for critical reading of this manuscript and M. Skoog for her valuable contribution.

Correspondence should be addressed to Dr. Sylvie Cazaubon, Centre National de la Recherche Scientifique UPR 0415, Institut Cochin de Génétique Moléculaire, 22 rue Méchain, 75014 Paris, France.

Copyright (C) 1997 Society for Neuroscience $\quad 0270-6474 / 97 / 176203-10 \$ 05.00 / 0$
1994). Consistent with the mitogenic activity of ET-1, ERK activation is now well recognized as an important process regulating mitogenesis and differentiation in response to numerous growth factors. In primary astrocytes, ET-1-induced activation of the $42 \mathrm{kDa}$ form of ERK (ERK2) requires the tyrosine phosphorylation of Shc and its subsequent association with Grb2, the adapter protein for the Ras guanine nucleotide exchange factor SOS. In addition, the protein serine/threonine-kinase Raf-1 is also involved in the ET-1-response, strongly suggesting that $\mathrm{ET}_{\mathrm{B}}$ receptors can be coupled to the Ras/Raf/ERK pathway initially associated with receptor tyrosine kinases (Lazarini et al., 1996).

The relationships between cell adhesion, cytoskeletal rearrangements, and cell growth are still poorly understood in neural cells. In peripheral cells, recent reports have illustrated the role of integrins in regulating anchorage-dependent proliferation (Richardson and Parsons, 1995). The integrins are a family of transmembrane receptors that bind to extracellular matrix (ECM) proteins at sites of focal adhesions, providing a physical link with the cytoskeleton as well as transducing signals. Among the proteins localized to focal adhesions, the cytosolic protein tyrosine kinases focal adhesion kinase (FAK) and Src and the cytoskeletal protein paxillin are involved in integrin signaling (Schaller and Parsons, 1994). The function of FAK is still not clear, though it is known to recruit SH2-containing proteins such as Src and Grb2 (Cobb et al., 1994; Schlaepfer et al., 1994). A link to the Ras/ Raf-1 signaling pathway is suggested by a number of reports indicating that the interaction of cells with ECM proteins results in activation of ERK (Schlaepfer et al., 1994; Morino et al., 1995). 
Moreover, a newly identified protein tyrosine kinase of the FAK subfamily, called proline-rich tyrosine kinase 2 (PYK2), has been found to be involved in ERK activation in neuronal cells (Lev et al., 1995).

In an attempt to clarify the mechanisms responsible for the anchorage-dependent proliferation of primary astrocytes in response to ET-1, the interactions between cell adhesion-related events and ERK activation pathway were investigated.

\section{MATERIALS AND METHODS}

Materials. Mouse monoclonal antibody specific to phosphotyrosine (4G10), Src, and ERK2 and rabbit polyclonal antibodies specific to FAK, Shc, and SOS were purchased from UBI (Lake Placid, NY). Rabbit polyclonal antibodies specific to Raf-1 were from Santa Cruz Biotechnology (Santa Cruz, CA). Polyclonal antibodies specific to PYK2 were produced by immunizing a rabbit against a 17 amino acid peptide encompassing residues 2-18 of rat PYK2, coupled to KLH with glutaraldehyde. Peroxidase-conjugated anti-mouse or anti-rabbit IgG antibodies and ECL reagents were from Amersham (Les Ulis, France). Mouse monoclonal antibody specific to phosphotyrosine (PY20) or to paxillin were from Transduction Laboratories (Lexington, KY). Mouse monoclonal antibody specific to vinculin, FITC-conjugated phalloidin, Bordetella pertussis toxin V (PTX), and cytochalasin D were from Sigma (St. Louis, MO). pGEX-2T-C3 was obtained from L. A. Feig (Tufts University School of Medicine, Boston, MA).

Expression and purification of C3-transferase. Glutathione $S$-transferase (GST)-C3 was expressed in Escherichia coli for $5 \mathrm{hr}$ using $1 \mathrm{~mm}$ isopropyl $\beta$-D-thiogalactopyranoside (Life Technologies, Gaithersburg, MD). Cells were harvested by centrifugation at $4000 \times g$ for $15 \mathrm{~min}$ and sonicated three times for $5 \mathrm{~min}$ in lysis buffer [ $50 \mathrm{~mm}$ Tris- $\mathrm{HCl}, \mathrm{pH} 8,50 \mathrm{~mm} \mathrm{NaCl}$, $5 \mathrm{mM} \mathrm{MgCl}_{2}, 1 \mathrm{~mm}$ DTT, and $1 \mathrm{~mm}$ 4-(2-aminoethyl)benzenesulfonyl fluoride (AEBSF)]. Bacterial lysates were then centrif ugated at 10,000 $\times$ $g$ for $30 \mathrm{~min}$, and the supernatant was chromatographed over glutathioneagarose. The column was washed with 5 vol of AEBSF-free lysis buffer and 3 vol of thrombin cleavage buffer $(50 \mathrm{~mm}$ Tris- $\mathrm{HCl}, \mathrm{pH} 8,150 \mathrm{~mm}$ $\mathrm{MgCl}_{2}, 2.5 \mathrm{mM} \mathrm{CaCl}_{2}$, and $1 \mathrm{mM}$ DTT). Bovine plasma thrombin (10 $\mathrm{U} / \mathrm{ml}$ gel) was then added to the column for $16 \mathrm{hr}$ at $4^{\circ} \mathrm{C}$. The eluate from the column was collected and subsequently washed with 3 vol of PBS. Thrombin was removed from $\mathrm{C} 3$-transferase protein released from the column by chromatography over $p$-aminobezamidine-agarose and dialyzed into PBS. C3-transferase protein was then concentrated in ultrafiltration units (Amicon, Beverly, MA). This procedure produced pure C3 protein as assessed by SDS-PAGE. Protein concentration was assessed using BCA reagent (Pierce, Rockford, IL).

Cell culture. Primary cultures of astrocytes were prepared as described previously (Lazarini et al., 1996). Striata and cortex were removed from brains of 17-d-old CD rat embryos and dissociated mechanically in serumfree medium. Cells were plated on poly-L-ornithine $(1.5 \mu \mathrm{g} / \mathrm{ml})$-precoated dishes $(60 \mathrm{~mm}$ diameter) in DMEM containing $1 \mathrm{gm} / 1$ glucose supplemented with $10 \%$ fetal calf serum and 10 mM HEPES, pH 7.4. On day 14, cytosine arabinoside at $1 \mu \mathrm{M}$ was added for $24 \mathrm{hr}$ to avoid the proliferation of microglial cells. Under these conditions, $>95 \%$ of the cells were stained positively by immunofluorescence technique using antibodies specific to glial fibrillary acid protein (Amersham). Treatments were performed on 18to 20-d-old cultures. Astrocytes were maintained in serum-free medium for $18 \mathrm{hr}$ before incubation with effectors (so-called quiescent astrocytes). Where indicated, the cells were pretreated for $18 \mathrm{hr}$ with $0.1 \mu \mathrm{g} / \mathrm{ml}$ PTX or $160 \mathrm{~nm}$ phorbol 12-myristate 13-acetate (TPA), for $24 \mathrm{hr}$ with $1.5 \mu \mathrm{g} / \mathrm{ml}$ C3-transferase, or for $2 \mathrm{hr}$ with $2 \mu \mathrm{M}$ cytochalasin D in serum-free medium before addition of the effectors.

Immunofluorescence. Astrocytes of 18- to 20-d cultures were replated on poly-L-ornithine $(1.5 \mu \mathrm{g} / \mathrm{ml})$-precoated glass coverslips. After $15 \mathrm{hr}$ in culture, cells were starved in serum-free medium and then treated with 50 nM ET-1 for $10 \mathrm{~min}$. After washes with PBS, the cells were fixed with paraformaldehyde (4\%) in PBS for $15 \mathrm{~min}$, protected with glycine $0.1 \mathrm{M}$ for $15 \mathrm{~min}$, and blocked with BSA (2\%)/saponin $(0.05 \%)$ PBS for $1 \mathrm{hr}$. The cells were incubated for $1 \mathrm{hr}$ with a monoclonal antibody specific to vinculin $(1 / 100)$ or PY20 $(2.5 \mu \mathrm{g} / \mathrm{ml})$ or with FITC-conjugated phalloidin for F-actin labeling. Anti-mouse antibodies conjugated to Cy3 (1/150) were used as secondary antibodies. Immunofluorescence images were collected in a scanner confocal microscope (MCR.1000, Bio-Rad, Hercules, CA).

Immunoprecipitation. Quiescent astrocytes were treated for $10 \mathrm{~min}$ with either ET-1 $(50 \mathrm{nM})$ or fluoroaluminate $\left(\mathrm{AlF}_{4}^{-} / 30 \mathrm{~mm}\right.$ sodium fluoride and $10 \mu \mathrm{M}$ aluminum chloride); these conditions of treatment have been shown to induce a maximum increase in tyrosine phosphorylation and activation of ERK (Cazaubon et al., 1993). After treatment, cells $\left(7.5 \times 10^{6}\right)$ were lysed in $400 \mu \mathrm{l}$ of $10 \mathrm{~mm}$ Tris-HCl, $\mathrm{pH} 7.5$, containing $140 \mathrm{~mm} \mathrm{NaCl}, 1 \% \mathrm{NP} 40,1 \mathrm{~mm}$ orthovanadate, $1 \mathrm{~mm}$ PMSF, $2 \mu \mathrm{g} / \mathrm{ml}$ aprotinin, $2 \mu \mathrm{g} / \mathrm{ml}$ pepstatin, and $2 \mu \mathrm{g} / \mathrm{ml}$ leupeptin (NP40 buffer). Cell lysates were incubated with the indicated antibodies for 15 hr at $4^{\circ} \mathrm{C}$ and then with $10 \mu \mathrm{l}$ of protein A-agarose (precoated with anti-mouse IgG for monoclonal antibody precipitation) for $1 \mathrm{hr}$. Immunoprecipitates were extensively washed in NP40 buffer and resuspended either in SDS-sample buffer and analyzed by immunoblotting (see below) or in kinase buffer and then autophosphorylated as described previously (Durieu-Trautmann et al., 1994).

Precipitation using GST-Grb2 and GST-Grb3-3. The fusion proteins GST-Grb2 and GST-Grb3-3 were produced as described previously (Cazaubon et al., 1993). The Grb3-3 protein is an isoform of Grb2 with a partially deleted SH2 domain (Fath et al., 1994). Cell lysates were incubated with either GST-Grb2 or GST-Grb3-3 bound to glutathionecoupled agarose beads for $15 \mathrm{hr}$ at $4^{\circ} \mathrm{C}$. The agarose beads were washed three times in NP40 buffer containing 1\% sodium deoxycholate and 300 $\mathrm{mm} \mathrm{NaCl}$, twice in NP40 buffer containing $1 \%$ sodium deoxycholate and $150 \mathrm{~mm} \mathrm{NaCl}$, and once in NP40 buffer containing 1\% sodium deoxycholate and $10 \mathrm{~mm} \mathrm{NaCl}$. Bound proteins were eluted with SDS-sample buffer and analyzed by immunoblot using indicated antibodies.

Immunoblot analysis. Immunoprecipitated proteins, proteins bound to the fusion proteins (GST-Grb2, GST-Grb3-3) or cell lysates, were analyzed by immunoblot as described previously (Cazaubon et al., 1993, 1994) using indicated antibodies at 0.5 to $2 \mu \mathrm{g} / \mathrm{ml}$. For serial incubations of a membrane, bound antibodies were stripped off by $0.1 \mathrm{M}$ glycine, $\mathrm{pH}$ 2.5 , for $10 \mathrm{~min}$, and the membrane was then reincubated with different antibodies as described above.

Immunofluorescence, immunoprecipitation, and immunoblot analysis on replated cells. Glass coverslips and $60 \mathrm{~mm}$ dishes were precoated for $1 \mathrm{hr}$ at room temperature with poly-L-ornithine $(1.5 \mu \mathrm{g} / \mathrm{ml})$. Quiescent serum-starved astrocytes were detached using trypsin/EDTA solution, and trypsin was inhibited by $0.5 \mathrm{mg} / \mathrm{ml}$ soybean trypsin inhibitor in serum-free medium. Cells were washed and resuspended in serum-free medium and allowed to attach to the coverslip or dish for $10 \mathrm{~min}, 60 \mathrm{~min}$, or $15 \mathrm{hr}$. Cells were then treated for $10 \mathrm{~min}$ with $50 \mathrm{~nm}$ ET-1. Immunofluorescence, immunoprecipitation, and immunoblot analysis were performed as described above.

$\left[{ }^{3} H\right]$ thymidine incorporation assay. Confluent astrocytes were trypsinized and seeded at a density of $1.7 \times 10^{4}$ cells/well in 96-well plates in normal growth culture medium. After $24 \mathrm{hr}$, culture medium was replaced by serum-free medium, and cells were incubated for an additional $24 \mathrm{hr}$. Astrocytes were then pretreated or not with $1.5 \mu \mathrm{g} / \mathrm{ml}$ C3-transferase or $2 \mu \mathrm{M}$ cytochalasin D for $2 \mathrm{hr}$ before stimulation with 50 nM ET-1. After incubation of cells for $21 \mathrm{hr}, 1 \mu \mathrm{Ci} /$ well [methyl${ }^{3} \mathrm{H}$ ] thymidine (48 Ci/mmol; Amersham) was added to the culture medium for an additional $3 \mathrm{hr}$ period. The medium was then removed, and cells were then detached by incubation with $50 \mu \mathrm{l}$ of a $0.5 \%$ trypsin $/ 0.2 \%$ EDTA solution for $5 \mathrm{~min}$ at $37^{\circ} \mathrm{C}$. Cells were collected on filters (Blue Mat 11740, Skatron, Lier, Norway) in a Skatron harvester (Sterling, VA), and the reactivity retained was counted in a $\beta$-plate liquid scintillation counter (Pharmacia, Uppsala, Sweden). The viability of the cells was not affected by the different treatments.

\section{RESULTS}

\section{ET-1 promotes the formation of stress fibers and focal adhesions in astrocytes}

To explore the regulation of cytoskeletal events by ET-1, confocal microscope analysis was conducted on astrocytes. The effect of ET-1 on the organization of F-actin was assessed using FITCconjugated phalloidin. Treatment of quiescent cells for $10 \mathrm{~min}$ with $50 \mathrm{~nm}$ ET-1 caused a marked increase in the formation of stress fibers (Fig. 1). The dramatic changes in the F-actin pattern was associated with marked modifications of cell morphology. Although quiescent astrocytes had very long and thin processes, cells treated with ET-1 were flattened, with actin cables at the cell periphery. Confocal microscope analysis revealed that the thickness of ET-1-treated cells was indeed reduced. Immunostaining for vinculin, a marker of focal adhesions, indicated that ET-1 

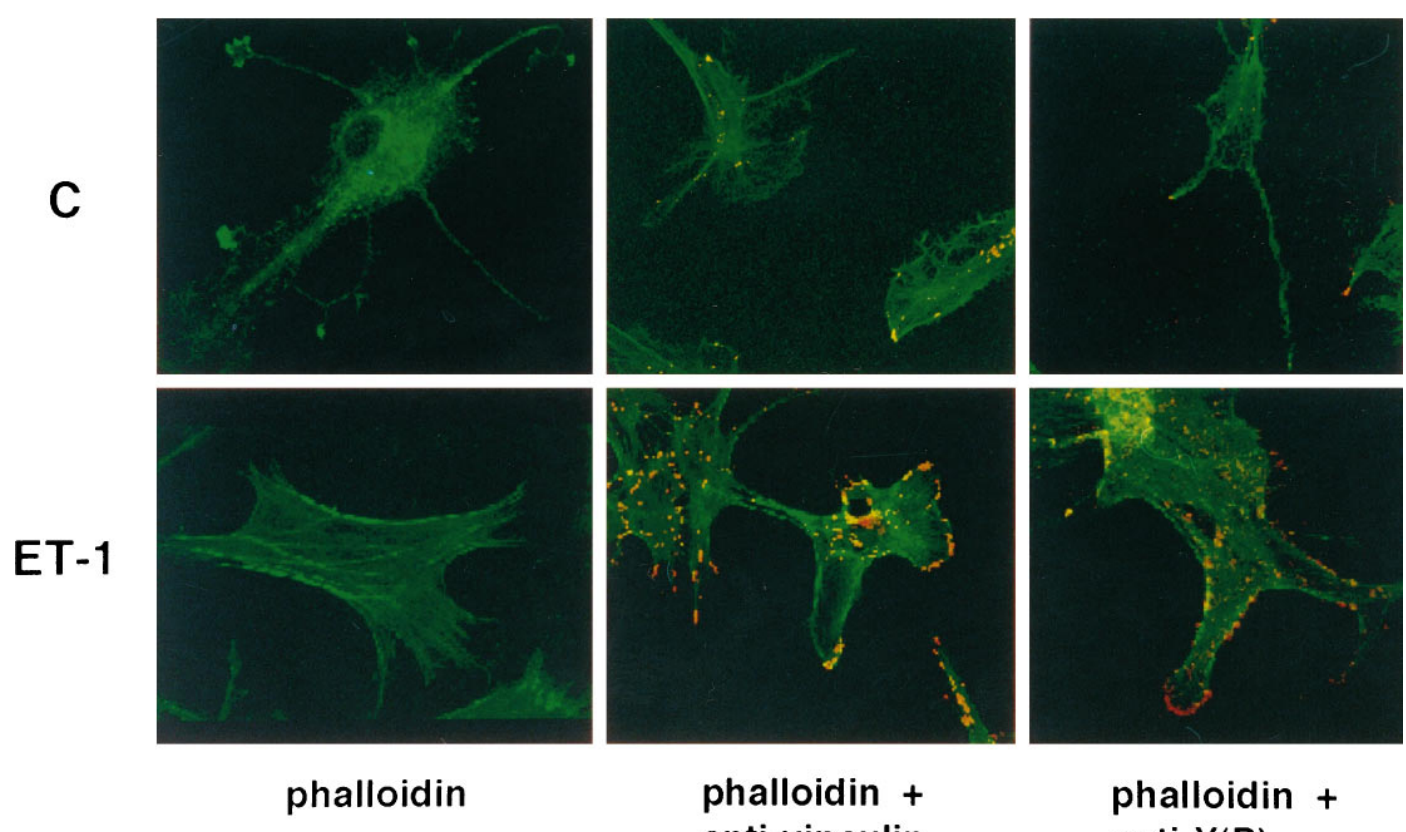

phalloidin +

phalloidin + anti-vinculin anti- $Y(P)$

Figure 1. Confocal analysis of the cytoskeleton organization in ET-1-treated astrocytes. Quiescent astrocytes (top row) or astrocytes treated with 50 nM ET-1 for $10 \mathrm{~min}$ (bottom row) were labeled using FITC-conjugated phalloidin (green), anti-vinculin antibodies, or anti-phosphotyrosine antibodies (PY20) plus anti-mouse antibodies conjugated to $\mathrm{Cy} 3$ ( red $)$. The results are representative of five independent experiments.

induced the formation of focal adhesions. Vinculin localized in elongated patches at stress fiber/plasma membrane contacts in ET-1-treated cells (Fig. 1). In correlation with the morphological changes, a marked increase in tyrosine phosphorylation was observed (Fig. 1). Comparable staining patterns with antiphosphotyrosine and anti-vinculin were detected, suggesting that focal adhesion proteins may be phosphorylated during ET-1 treatment.

\section{ET-1 induces FAK and paxillin tyrosine phosphorylation as well as Src activation through a PTX-insensitive G- protein-dependent pathway}

In primary cultures of astrocytes, ET-1 was previously reported to stimulate tyrosine phosphorylation of several cellular proteins with a maximum at $10 \mathrm{~min}$ (Cazaubon et al., 1993). Prominent phosphorylation of proteins of 110-130 kDa together with ET-1induced tyrosine phosphorylation of proteins localized at stress fiber/plasma membrane contacts (Fig. 1) suggested that FAK could be involved in the response of astrocytes to ET-1. Recent reports have begun to delineate substrates of FAK, showing that autophosphorylation of FAK may serve to recruit Src to focal adhesions (Schlaepfer et al., 1994); substrates of the FAK/Src complex may include the cytoskeletal protein paxillin. The ability of ET-1 (50 nM) to induce these responses was examined in astrocytes treated for $10 \mathrm{~min}$, conditions in which the increase in tyrosine phosphorylation was maximum. Immunoblot analysis of immunoprecipitated proteins with anti-phosphotyrosine antibodies revealed that ET-1 stimulates the tyrosine phosphorylation of both FAK and paxillin (3.5- and 2-fold, respectively) (Fig. 2). In addition, the increase in tyrosine phosphorylation of FAK correlated with its activation, because immunoprecipitated FAK from ET-1-treated cells was able to autophosphorylate (not shown). The ability of ET-1 to stimulate Src activity was examined by determining the ability of immunoprecipitated Src to undergo autophosphorylation. Densitometric scanning analysis indicated that ET-1 induced a 2.5-fold increase in phosphorylated Src (Fig. 2). A slight phosphorylation of heavy chains of immunoglobulins was also detected in immunocomplexes from ET-1-treated cells. To further investigate the mechanisms responsible for these responses, the involvement of heterotrimeric G-proteins and PKC was evaluated. As shown in Figure 2, direct activation of heterotrimeric G-proteins by $\mathrm{AlF}_{4}^{-}$mimicked the ability of ET-1 to activate FAK and Src. Responses to ET-1 were affected by neither PTX pretreatment nor long-term treatment of cells with TPA (not shown). Altogether, these results indicate that ET-1 induces the activation/phosphorylation of FAK, Src, and paxillin by a PTX-insensitive G-protein-dependent and PKC-independent mechanism.

\section{Binding of tyrosine-phosphorylated FAK to the $\mathrm{SH} 2$ domain of Grb2 in ET-1- and AlF 4 -treated astrocytes}

A recent report has shown that phosphorylation of FAK in response to integrin activation may result in its association with the adapter protein Grb2 (Schlaepfer et al., 1994). In astrocytes, we have shown previously that ET-1 induces the association of Shc to Grb2, leading to ERK activation (Cazaubon et al., 1994). To explore the possibility that FAK and/or Src might participate in these events, interaction between these protein tyrosine kinases and Grb2 was examined. Cells were treated with either ET-1 or $\mathrm{AlF}_{4}^{-}$, a direct activator of heterotrimeric G-proteins, and the ability of Src or FAK to interact with the GST-Grb2 fusion protein immobilized on glutathione-agarose beads was determined by immunoblotting. As shown in Figure $3 \mathrm{~A}$ (left panels), FAK bound to Grb2 under conditions in which Shc-Grb2 interaction was induced, whereas no association of Src was detected (not shown). The specificity of this interaction was confirmed by the observation that FAK, like Shc, did not bind to Grb3-3, a Grb2 isoform with a nonf unctional SH2 domain (Fath et al., 1994). These results indicate that Grb2 interacts with FAK and Shc through its $\mathrm{SH} 2$ domain. Reincubation of the same 


\section{WB anti-Y(P)}

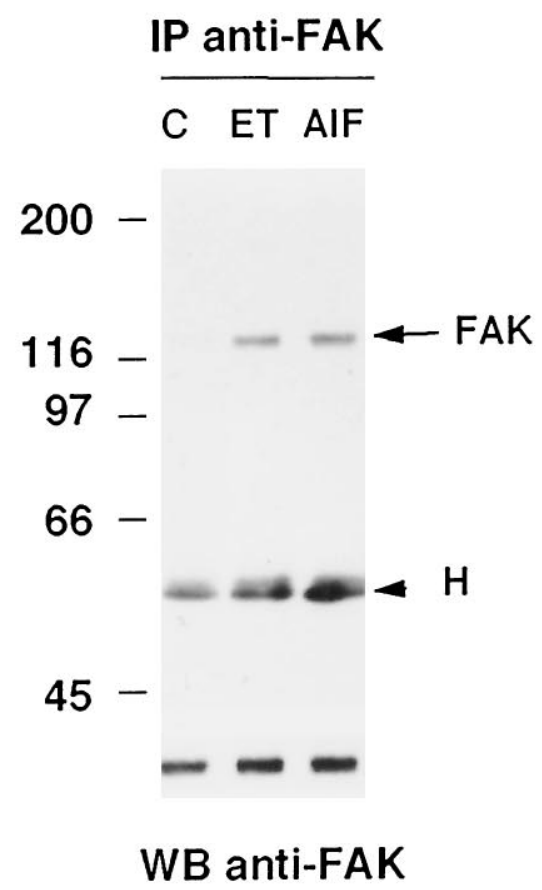

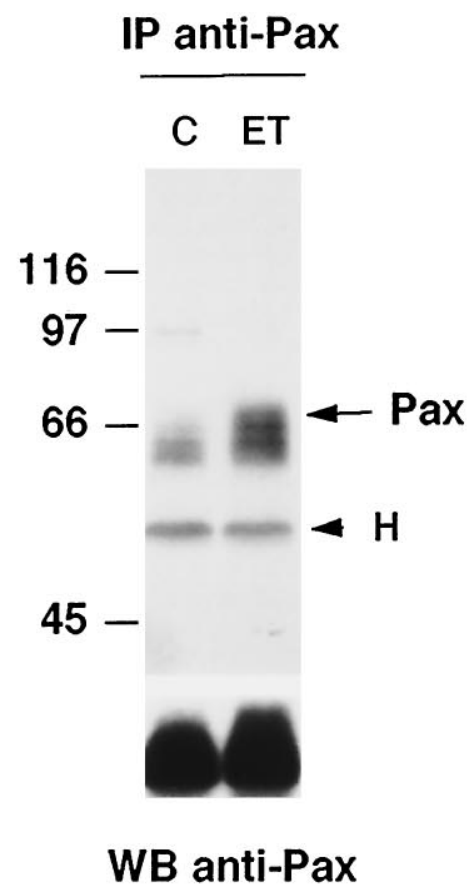

Auto(P)

IP anti-Src

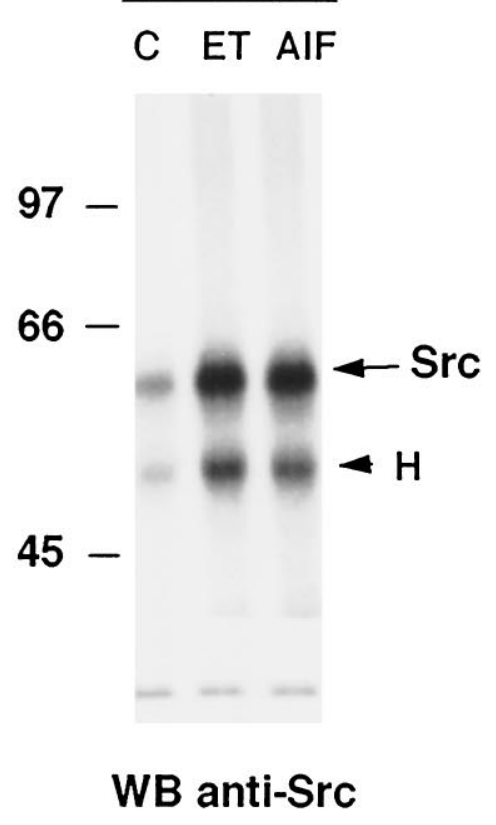

Figure 2. Tyrosine phosphorylation or autophosphorylation of immunoprecipitated FAK, paxillin, and Src in ET-1-treated astrocytes. Lysates from untreated quiescent astrocytes $(C)$ and those treated for 10 min with $50 \mathrm{nM}$ ET- $1(E T)$ or $\mathrm{AlF}_{4}^{-}(30$ mM sodium fluoride and $10 \mu \mathrm{M}$ aluminum chloride) $(A l F)$ were immunoprecipitated with anti-FAK $(1 \mu \mathrm{g})$, anti-paxillin (anti-Pax) $(2.5 \mu \mathrm{g})$, or anti-Src $(2.5 \mu \mathrm{g})$ antibodies, respectively. Immunoprecipitated proteins were analyzed either by immunoblotting with anti-phosphotyrosine antibodies $[W B$ anti- $Y(P)$ : IP anti-FAK, IP anti-Pax] or by their ability to undergo autophosphorylation $[A u t o(P)$ : IP anti-Src]. After stripping of the bound antibodies, the same membrane was reincubated with anti-FAK, anti-Pax, and anti-Src antibodies, respectively, showing that a comparable amount of proteins was immunoprecipitated. Molecular mass markers (kDa) are shown on the left side. Arrowheads indicate the heavy chain of immunoglobulins $(H)$, and arrows indicate the migration of the immunoprecipitated proteins $F A K$, Pax, or Src. The results are representative of three independent experiments.

membrane with anti-phosphotyrosine antibodies revealed that bound FAK and Shc were indeed tyrosine-phosphorylated (Fig. $3 A$, right panels). Consistent with a constitutive association of SOS with the SH3 domains of Grb2, its interaction with Grb2 or Grb3-3 was detected in either untreated or treated astrocytes; however, under conditions in which Shc and FAK bound to Grb2, the electrophoretic mobility of SOS appeared slightly decreased (Fig. 3A), suggesting that phosphorylation of SOS might occur during ET-1 or $\mathrm{AlF}_{4}^{-}$treatment (Seger and Krebs, 1995). Altogether, these results indicate that ET-1, as well as G-protein stimulation, might promote the interaction of the phosphorylated forms of Shc and FAK with the Grb2-SOS complex. These responses increased simultaneously as a function of ET-1 concentration, a maximal response being observed in astrocytes treated with 50 nм ET-1 (Fig. 3B, left panels). The time courses of these interactions were similar, in that binding of Shc and FAK to Grb2 was detectable within $5 \mathrm{~min}$ after exposure of ET-1 (50 nM), reached a peak at $10 \mathrm{~min}$ and returned to basal level at $60 \mathrm{~min}$ of treatment (Fig. 3B, right panels).

\section{Activation of the ERK2 pathway induced by ET-1 is independent of FAK/Src recruitment and stress fiber formation}

To evaluate the contribution of FAK and Src in the regulation of the ERK pathway coupled to ET receptors, activation of this cascade was determined in astrocytes pretreated with $2 \mu \mathrm{M} \mathrm{cy-}$ tochalasin D for $2 \mathrm{hr}$. Under these conditions, ET-1 was unable to promote the formation of stress fibers and focal adhesions in astrocytes (not shown). Moreover, this pretreatment completely prevented the ET-1-induced phosphorylation of FAK, paxillin, and Src, indicating that both protein tyrosine kinases require actin-based cytoskeletal integrity for activation (Fig. 4A, left panels). In contrast, the association of Shc to Grb2 or the detection of the shifted form of SOS remained largely unmodified in astrocytes pretreated with cytochalasin D (Fig. 4A, right panels). Neither Raf-1 nor ERK2 phosphorylation was hindered, as visualized by slower migration of phosphorylated forms during immunoblot analysis (Fig. 4A, right panels).

A member of the small GTP-binding protein family, Rho, has been shown to mediate the activation of FAK after stimulation of some receptors coupled to heterotrimeric G-proteins in fibroblasts (Craig and Johnson, 1996). In astrocytes, specific inactivation of Rho with C3-transferase blocks not only FAK but also Src activation induced by ET-1 (Fig. 4B, left panels). As expected, tyrosine phosphorylation of paxillin was also prevented by C3transferase pretreatment. As observed in cytochalasin D-pretreated astrocytes, the activation of the ERK pathway by ET-1 was not significantly affected by the C3-transferase pretreatment (Fig. 4B, right panels). The time course of ET-1-induced ERK2 activation after C3-transferase or cytochalasin D pretreatment was also not modified (not shown). Altogether, these results indicate that integrity of the cytoskeleton and activation of Rho are required for FAK and Src activation after ET-1 stimulation, 


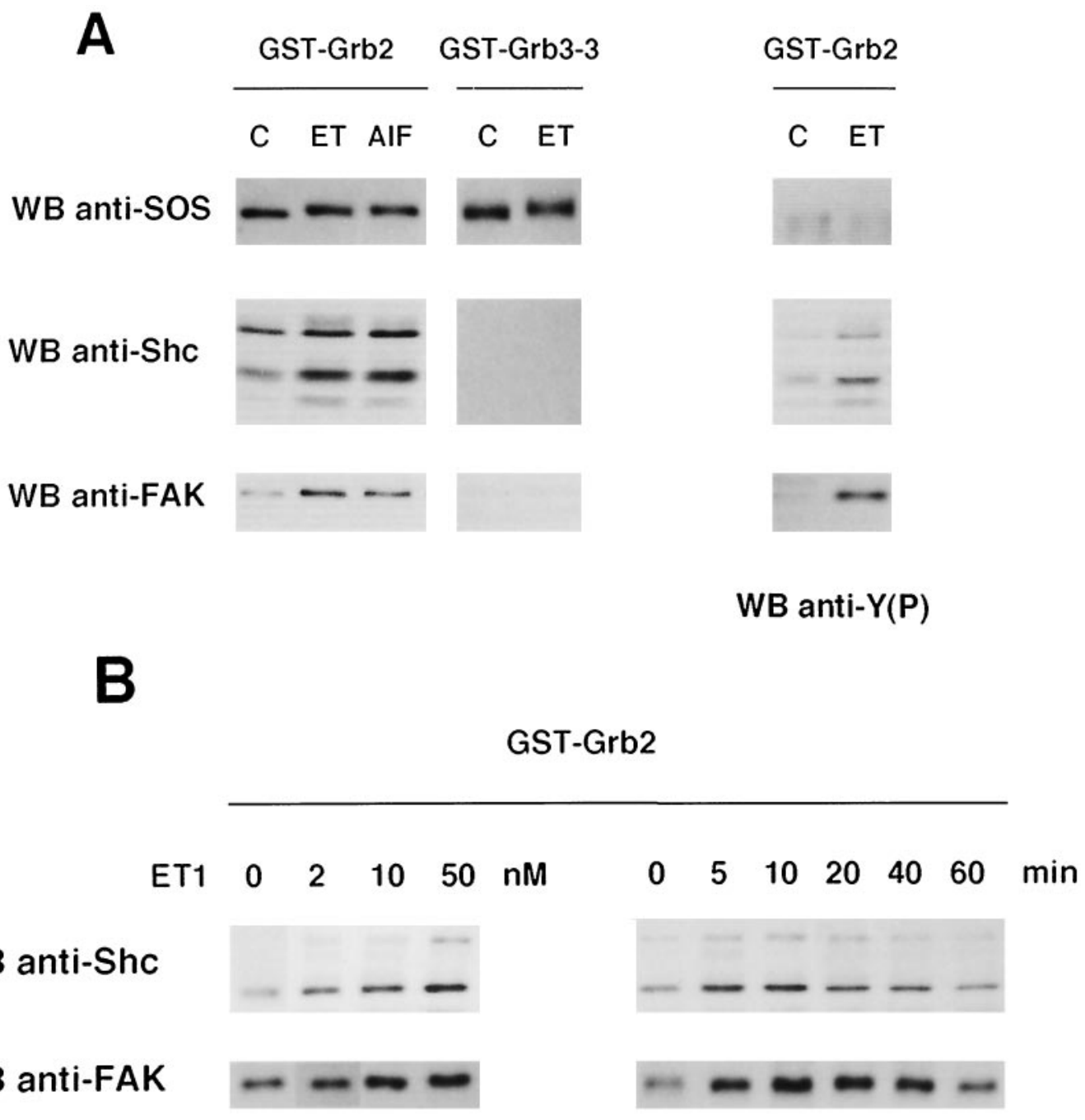

Figure 3. Association of tyrosine-phosphorylated FAK and Shc to the SH2 domain of Grb2 in ET-1-treated astrocytes. $A$, Quiescent astrocytes were not treated $(C)$ or were treated for 10 min with either $50 \mathrm{~nm} \mathrm{ET-1}(E T)$ or $\mathrm{AlF}_{4}^{-}$(30 mM sodium fluoride and $10 \mu \mathrm{M}$ aluminum chloride) $(A l F)$, and the ability of SOS, Shc, and FAK to interact with either the GST-Grb2 or GST-Grb3-3 fusion proteins, immobilized on glutathione-agarose beads, was determined by immunoblotting with anti-SOS, anti-Shc, or anti-FAK antibodies, respectively. After stripping of the bound antibodies, the membrane was reincubated with anti-phosphotyrosine antibodies $[W B$ anti- $Y(P)]$. B, Lysates from astrocytes untreated (0), treated for 10 min with ET-1 at the indicated concentrations $(2,10,50 \mathrm{~nm})$ (left), or treated with $50 \mathrm{~nm}$ ET-1 for the indicated times $(5,10,20,40,60$ min) (right) were precipitated with GST-Grb2. Bound proteins were analyzed by immunoblotting with either anti-Shc or anti-FAK antibodies. The results are representative of three independent experiments.

whereas the ERK pathway seems to be mostly Rho, FAK, and Src independent.

\section{ET-1-induced tyrosine phosphorylation of PYK2 by a PTX-insensitive G-protein-dependent Rho- and PKC- independent pathway}

The newly identified protein tyrosine kinase PYK2 has been shown to lead to ERK activation in PC12 cells (Lev et al., 1995). To determine the putative contribution of PYK2 in the response of astrocytes to ET-1, immunoprecipitation analysis with specific antibodies was performed (Fig. 5). Results indicate that PYK2 is expressed in primary astrocytes. Furthermore, ET-1 induced a threefold increase of PYK2 tyrosine phosphorylation, and this effect was mimicked by $\mathrm{AlF}_{4}^{-}$. The ET-1-induced response was essentially not affected by PTX pretreatment, indicating that a G-protein distinct from $\mathrm{G}_{\mathrm{i}} / \mathrm{G}_{\mathrm{o}}$ is involved. As previously reported in PC12 cells, activation of PKC by TPA lead to PYK2 phosphorylation (Fig. 5). Although the downregulation of PKC activity by long-term treatment with TPA completely abolished further TPA effect, phosphorylation of PYK2 induced by ET-1 remained largely unchanged. As shown previously (Cazaubon et al., 1993), ERK2 activation induced by ET-1 was partially inhibited in TPApretreated cells. The ET-1-induced phosphorylation of PYK2 was also insensitive to pretreatment of the cells with either cytochalasin D or C3-transferase under conditions in which activation of the ERK2 pathway was observed (Figs. $4 A, B, 5$ ). A slight crossreactivity of anti-ERK2 antibodies with the $44 \mathrm{kDa}$ form of ERK, ERK1, can be detected with increasing time of exposure of autoradiographies (Fig. 5, and data not shown from experiments presented in Figs. 4 and 6), indicating that ERK1 is also activated after ET-1 treatment as determined previously (Cazaubon et al., 1993). Collectively, these results indicate that tyrosine phosphorylation of PYK2 coincides with activation of ERK2 (and ERK1) in ET-1-treated astrocytes and that both responses are independent of Rho and cytoskeletal integrity. 
A

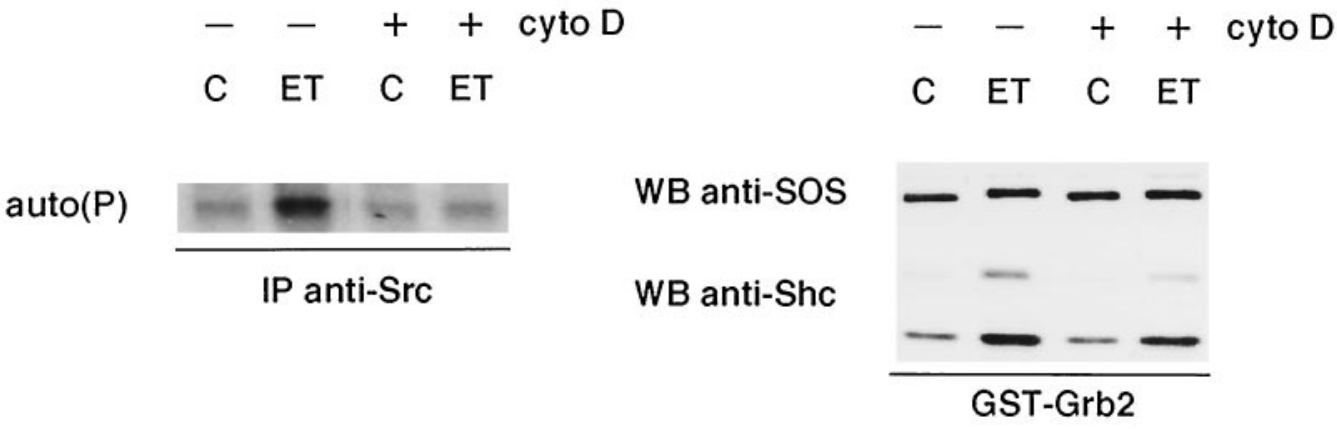

WB anti- $Y(P)$

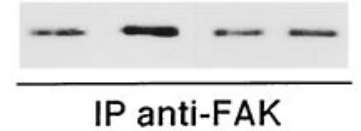

WB anti-Y(P)

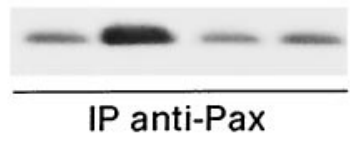

B

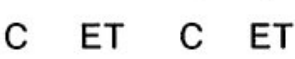

auto(P)

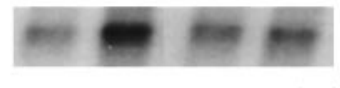

IP anti-Src

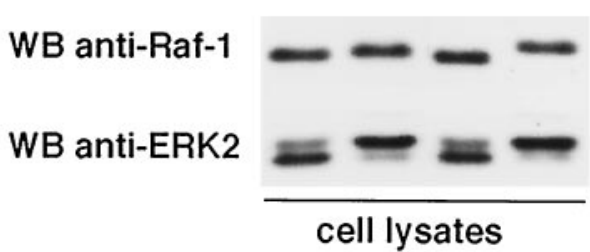

$-\quad++\mathrm{C} 3$

C ET C ET
WB anti-SOS

WB anti-Shc

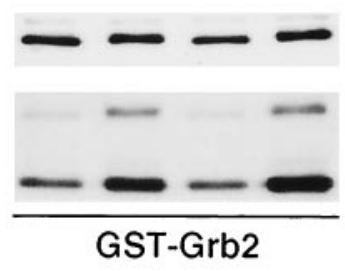

GST-Grb2

WB anti-Raf-1

WB anti-ERK2

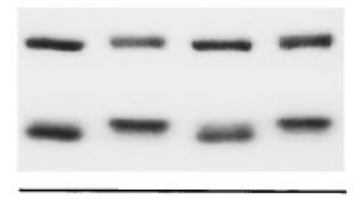

cell lysates

IP anti-Pax

Figure 4. Effect of cytochalasin D and C3-transferase pretreatment on the ET-1 responses of astrocytes. Quiescent astrocytes were pretreated either with $2 \mu \mathrm{M}$ cytochalasin D for $2 \mathrm{hr}(A)$ or with $1.5 \mu \mathrm{g} / \mathrm{ml}$ of C3 for $24 \mathrm{hr}(B)$ before addition of $50 \mathrm{~nm}$ ET-1 for 10 min $(E T)$; untreated cells $(C)$. Cell lysates were then submitted to precipitation with GST-Grb2 fusion protein plus immunoblotting with either anti-SOS (1 $\mu \mathrm{g} / \mathrm{ml})$ or anti-Shc antibodies $(1 \mu \mathrm{g} / \mathrm{ml})($ GST-Grb2); immunoblot analysis using anti-Raf-1 $(1 \mu \mathrm{g} / \mathrm{ml})$ and anti-ERK2 antibodies $(0.5 \mu \mathrm{g} / \mathrm{ml})($ cell lysates $)$; immunoprecipitation with anti-FAK $(1 \mu \mathrm{g})$, anti-paxillin (anti-Pax) $(2.5 \mu \mathrm{g})$, or anti-Src $(2.5 \mu \mathrm{g})$ antibodies, respectively. Immunoprecipitated proteins were analyzed either by immunoblotting with anti-phosphotyrosine antibodies $[W B$ anti- $Y(P)$, IP anti-FAK, IP anti-Pax] or by their ability to undergo autophosphorylation $[$ auto $(P): I P$ anti-Src]. The results are representative of four independent experiments.

\section{Induction of stress fiber formation and activation of FAK/Src by ET-1 is dependent on cell adhesion}

In an attempt to determine the contribution of cell adhesion in ET-1-induced responses, matrix attachment was abolished by replating quiescent astrocytes on poly-L-ornithine-precoated coverslips and dishes 10 or 60 min before treatment with ET-1. As shown by confocal microscope analysis (Fig. $6 A$ ), even after ET-1 treatment, cells rounded; labeling with phalloidin showed that stress fibers were not assembled under these conditions. These F-actin patterns were clearly different from stress fibers induced in cells adhering for $15 \mathrm{hr}$ before ET-1 treatment (Figs. 1, 6A), a time compatible with the cellular production of ECM proteins and the involvement of integrins in cell adhesion (Tawil et al., 1993). Consistent with the absence of focal adhesion formation 

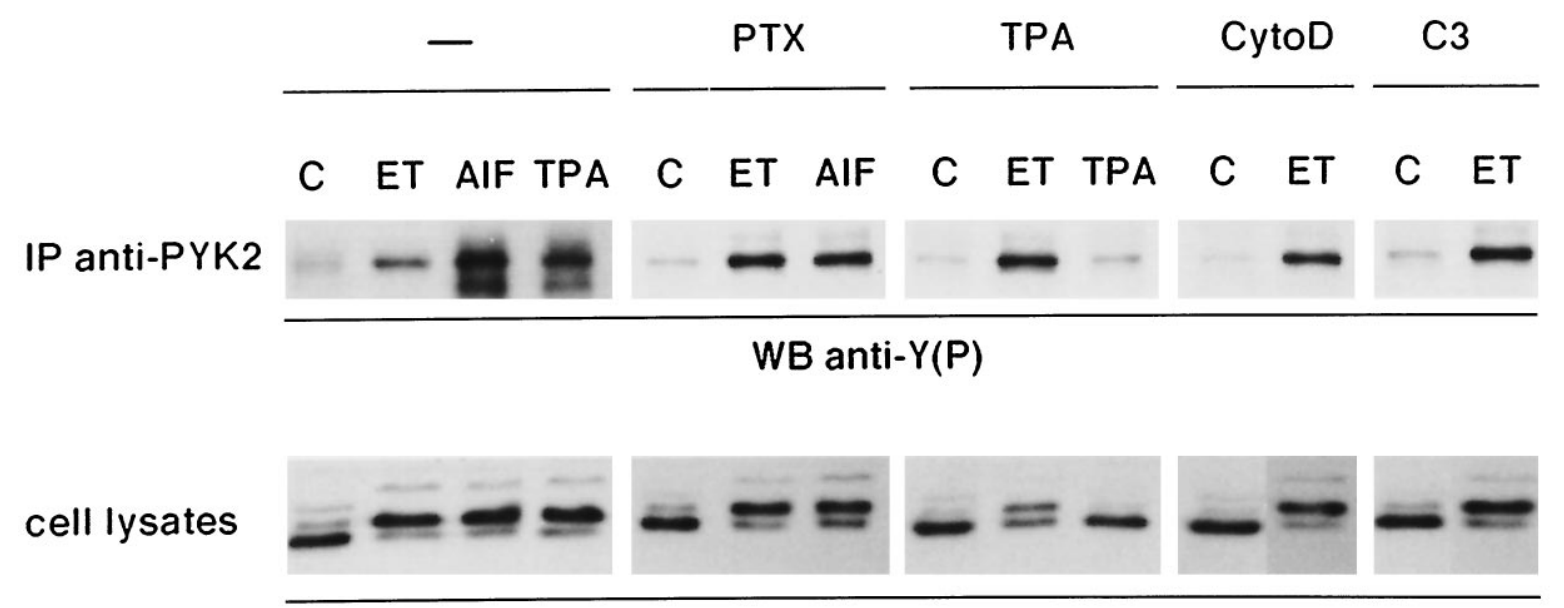

WB anti-ERK2

Figure 5. Tyrosine phosphorylation of immunoprecipitated PYK2 in ET-1- and AlF-treated astrocytes. Astrocytes were not pretreated (-) or were pretreated for $18 \mathrm{hr}$ with $0.1 \mu \mathrm{g} / \mathrm{ml} P T X$ or $160 \mathrm{~nm} T P A$ for $24 \mathrm{hr}$ with $1.5 \mu \mathrm{g} / \mathrm{ml} \mathrm{C} 3$-transferase $(C 3)$, or for $2 \mathrm{hr}$ with $2 \mu \mathrm{M}$ cytochalasin D $(C y t o D)$ in serum-free medium before addition of effectors for $10 \mathrm{~min}$ : $50 \mathrm{~nm} \mathrm{ET-1}(E T), \mathrm{AlF}_{4}^{-}$(30 mM sodium fluoride and $10 \mu \mathrm{M}$ aluminum chloride) $(A l F)$, or $160 \mathrm{~nm} T P A$; untreated cells $(C)$. Cell lysates were then submitted either to immunoblot analysis using anti-ERK2 antibodies $(0.5 \mu \mathrm{g} / \mathrm{ml})($ cell lysates) or to immunoprecipitation with anti-PYK2 antibodies $(10 \mu \mathrm{l})$. Immunoprecipitated proteins were analyzed by immunoblotting with anti-phosphotyrosine antibodies $[W B$ anti- $Y(P)]$. The results are representative of three independent experiments.

(not shown), tyrosine phosphorylation of FAK, paxillin, and Src was reduced dramatically in astrocytes replated 10 or $60 \mathrm{~min}$ before treatment with ET-1 (Fig. 6B). In contrast, PYK2 and ERK2 phosphorylation induced by ET-1 occurred in these cells. Analysis of the electrophoretic mobility of ERK2 in untreated astrocytes revealed that trypsinization by itself resulted in a limited activation of ERK2, detectable 10-60 min after cells were replated; however, this response was largely increased in response to ET-1. These results indicate that attachment to ECM is not necessary for ET-1-induced PYK2 and ERK2 phosphorylation in astrocytes. In contrast, FAK/Src activation after ET-1 stimulation requires cell adhesion. This conclusion was supported by the observation that ET-1-induced FAK phosphorylation was recovered in astrocytes $60 \mathrm{~min}$ after replating on collagen-precoated dishes (not shown).

\section{Stimulation of DNA synthesis induced by ET-1 is dependent on Rho activation and cytoskeletal integrity}

ERK activation is now well recognized as an important process regulating mitogenesis and differentiation in response to numerous growth factors (Seger and Krebs, 1995). In glioma cells and primary astrocytes, ET-1 has been reported to stimulate $\left[{ }^{3} \mathrm{H}\right]$ thymidine incorporation accompanying the activation of ERK2 (MacCumber et al., 1990; Lazarini et al., 1996). Because ERK2 activation was shown to be independent of cell adhesion in primary astrocytes, the contribution of an adhesion-dependent pathway to the increase in DNA synthesis induced by ET-1 was evaluated. In control cells, ET-1 led to a 2.9-fold increase of $\left[{ }^{3} \mathrm{H}\right]$ thymidine incorporation over basal levels (Fig. 7). Pretreatment of the cells with either cytochalasin D or C3-transferase largely prevented this response, indicating that both Rho activation and cytoskeletal integrity are critical for the observed effect. These results suggest that activation of ERK2 may be necessary but not sufficient for the increase in DNA synthesis induced by ET-1 and that an adhesion-dependent pathway is also involved in this response.

\section{DISCUSSION}

The present study was aimed at investigating the dependence of ET-1-induced ERK activation in astrocytes on cytoskeletal organization and adhesion to ECM. ET-1 caused a marked increase of stress fiber and focal adhesion formation associated with modifications of cell morphology. In correlation with these changes, an important increase in tyrosine phosphorylation of focal adhesion proteins was observed, including the protein tyrosine kinases FAK and Src and the cytoskeletal protein paxillin. These responses, together with DNA synthesis, were dependent on actin cytoskeleton integrity, Rho activation, and adhesion to ECM. By contrast, ERK2 activation by ET-1 was found to be independent of these events and to coincide with PYK2 phosphorylation (Fig. 8).

The molecular mechanisms responsible for increased tyrosine phosphorylation of focal adhesion proteins after stimulation of G-protein-coupled receptors are still unclear. In primary astrocytes, activation of FAK and Src by ET-1 was found to be dependent on Rho and a PTX-insensitive G-protein and independent of PKC. These findings provide the first demonstration that Rho can participate in Src activation after stimulation of heterotrimeric G-protein-coupled receptors such as ET receptors. Moreover, concomitant activations of FAK and Src were also found to require cytoskeletal integrity and cell adhesion to ECM proteins, including collagen, suggesting that ET-1 might indeed trigger integrin pathways. The formation of focal adhesions induced by ET-1 also supports the idea that this neuropeptide can promote further integrin engagement. Responses mediated by other G-protein-coupled receptors have also been reported to be dependent on adhesion through integrins, such as thrombininduced aggregation of platelets, a process that leads to tyrosine phosphorylation of FAK (Shattil et al., 1994). Moreover, it has been shown recently in Swiss 3 T3 fibroblasts that integrin signaling is a consequence of Rho activation rather than simple binding to ECM proteins (Hotchin and Hall, 1995). Altogether, these data indicate that cross-talk between ET receptors and integrins 
A

C
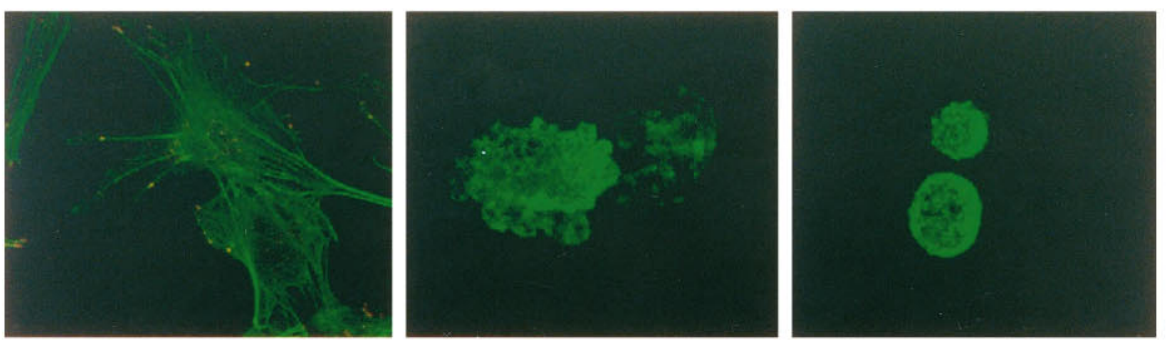

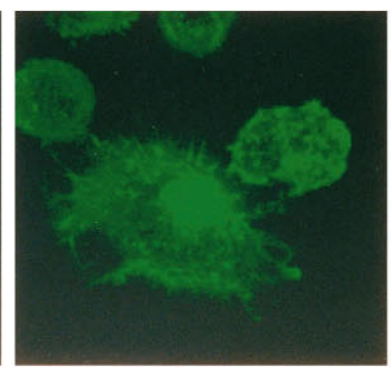

$60 \min$

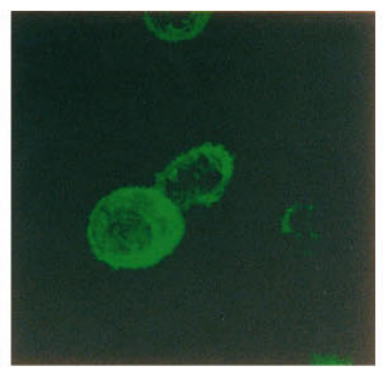

$10 \min$
B

IP anti-Src

$\frac{15 \mathrm{~h}}{C \quad E T} \frac{60 \mathrm{~min}}{C \quad E T} \quad \frac{10 \mathrm{~min}}{C \quad E T}$

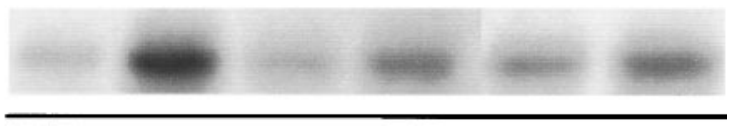

Auto(P)

IP anti-FAK

IP anti-Pax

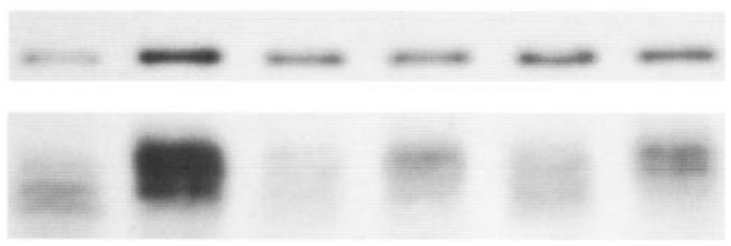

IP anti-PYK2

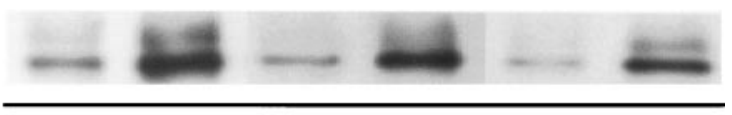

WB anti-Y(P)

cell lysates

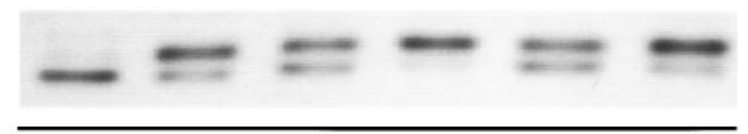

WB anti-ERK2
Figure 6. Effect of matrix attachment on the ET-1 responses of astrocytes. Quiescent serum-starved astrocytes were replated on precoated poly-L-ornithine glass coverslips or dishes of $60 \mathrm{~mm}$ diameter. Cells were allowed to attach $10 \mathrm{~min}, 60 \mathrm{~min}$, or $15 \mathrm{hr}$ before treatment with $50 \mathrm{nM}$ ET-1 for $10 \mathrm{~min}(E T)$; untreated cells (C). A, Confocal analysis of the cytoskeleton organization using FITC-conjugated phalloidin ( green). $B$, Cell lysates were submitted either to immunoblot analysis using anti-ERK2 antibodies $(0.5$ $\mu \mathrm{g} / \mathrm{ml}$ ) (cell lysates) or to immunoprecipitation with anti-Src $(2.5$ $\mu \mathrm{g})$, anti-FAK $(1 \mu \mathrm{g})$, anti-paxillin (anti-Pax) $(2.5 \mu \mathrm{g})$, or antiPYK2 antibodies $(10 \mu \mathrm{l})$, respectively. Immunoprecipitated proteins were analyzed either by their ability to undergo autophosphorylation $[$ Auto $(P)]$ or by immunoblotting with antiphosphotyrosine antibodies $[W B$ anti- $Y(P)]$. The results are representative of four independent experiments. might occur in astrocytes with regard to Rho-dependent activation of FAK/Src.

Among cytosolic tyrosine kinases, tyrosine-phosphorylated FAK has been proposed to provide a potential link to ERK activation after integrin stimulation (Schlaepfer et al., 1994). Also, members of the Src family have been involved in the coupling of some receptors with seven transmembrane domains to the Ras/Raf/ERK pathway (Luttrell et al., 1996; Sadoshima and Izumo, 1996; Wan et al., 1996). At variance with these observations, neither FAK nor Src activation was required for ERK2 activation induced by ET-1 in astrocytes. Although ET-1induced phosphorylation of FAK can lead to the association with Grb2, formation of the FAK-Gbr2 complex was dispensable for ERK activation. Accordingly, a FAK-independent pathway leading to ERK activation after integrin engagement has also been demonstrated recently in non-neural cells (Wary et al., 1996). 


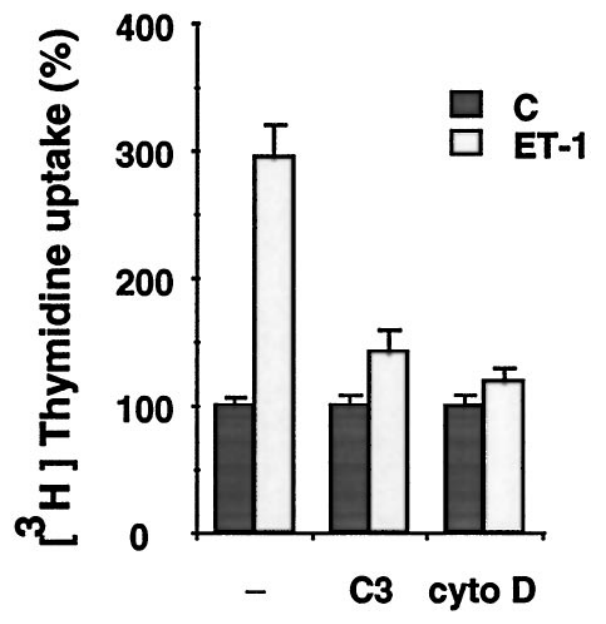

Figure 7. Effect of cytochalasin D and C3-transferase pretreatment on $\left[{ }^{3} \mathrm{H}\right]$ thymidine uptake in ET-1-treated astrocytes. Quiescent astrocytes in 96-well plates were not pretreated ( - ) or were pretreated either with 1.5 $\mu \mathrm{g} / \mathrm{ml}$ of C3-transferase $(C 3)$ or $2 \mu \mathrm{M}$ cytochalasin D for $2 \mathrm{hr}$ (cyto D) before incubation with $50 \mathrm{~nm}$ ET-1 (ET-1) for $24 \mathrm{hr}$; untreated cells $(C)$. $\left[{ }^{3} \mathrm{H}\right]$ thymidine $(1 \mu \mathrm{Ci} /$ well $)$ was added $3 \mathrm{hr}$ before the cells were harvested. Data are means of 12 determinations \pm SEM and expressed as percentages of $\left[{ }^{3} \mathrm{H}\right]$ thymidine uptake of untreated cells $(280 \pm 18)$. The results are of one experiment representative of three.

Altogether, these observations suggest that diverse molecular mechanisms may couple ERK activation to membrane receptors, likely in a cell-specific manner. In primary astrocytes, the newly identified member of the FAK subfamily, PYK2, was found to be tyrosine-phosphorylated concomitantly with ERK2 activation. Both responses are indeed mediated by a PTX-insensitive
G-protein-dependent and Rho-independent pathway. In agreement with the lack of involvement of FAK/Src in the ERK2 pathway induced by ET-1, PYK2 and ERK2 can be fully activated by this neuropeptide in the absence of cytoskeletal integrity and matrix attachment. Because activation of PYK2 by bradykinin, a ligand of a G-protein-coupled receptor, has been shown to lead to ERK activation in PC12 cells (Lev et al., 1995), it is likely, from our observations, that PYK2 plays a similar role in the response of astrocytes to ET-1.

Cytoskeletal integrity and Rho activation were found to be essential for efficient DNA synthesis in ET-1-treated primary astrocytes. These observations suggest that ET-1-induced ERK2 activation is not sufficient for proliferation of normal astrocytes. Although the physiological functions of the FAK/Src signals remain to be clarified further, they might constitute a preliminary crucial step to cell proliferation, ensuring that only adherent astrocytes can proliferate. Consistent with this observation, many transformed cells, including gliomas, do not require adhesion to ECM proteins for proliferation or migration. It is also noteworthy that altered communication between gliomas or brain metastatic tumor cells and ECM is indeed responsible for clinically important features such as cerebral invasion and leptomeningeal spread (Menter et al., 1995; Paulus and Tonn, 1995).

At the level of the blood-brain barrier, ET-1 is involved in the control of cerebral circulation but also in a number of physiological processes, such as cell proliferation and hormone secretion (Cazaubon and Couraud, 1997). Microvascular endothelial cells are responsible for local ET-1 production in brain, and this response can be positively stimulated by thrombin and cytokines. In conditions of inflammation, ET-1 can therefore contribute to the associated astrocytic response, including reactive gliosis.

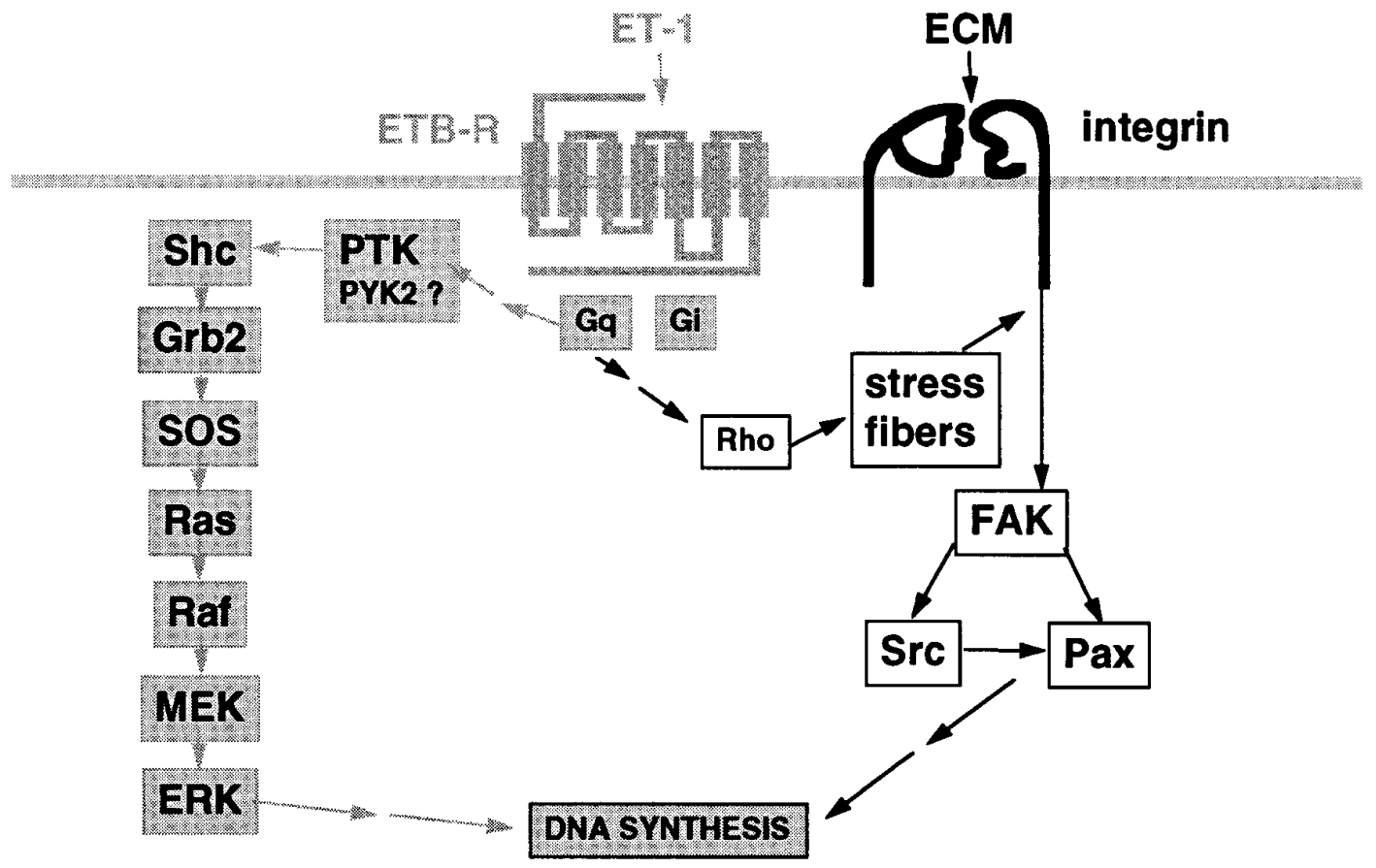

Figure 8. Schematic representation of adhesion-dependent and -independent pathways leading to DNA synthesis in ET-1-treated astrocytes. Primary astrocytes express ET-1-receptors $\left(\mathrm{ET}_{\mathrm{B}}-\mathrm{R}\right.$ subtype) coupled via PTX-insensitive heterotrimeric G-proteins $\left(\mathrm{G}_{\mathrm{q}}\right)$ to at least two distinct pathways: (1) the adhesion-independent activation of the ERK pathway ( gray arrows) initiated by phosphorylation of Shc by a protein tyrosine kinase (PTK); PYK2 activation coincides with ERK activation and could be responsible for this phosphorylation event; and (2) the adhesion-dependent activation of FAK/Src pathway (black arrows), which requires Rho activation and stress fiber formation. Adhesion of astrocytes to ECM proteins involves integrins, heterodimeric receptors composed of $\alpha$ and $\beta$ chains. Both signaling pathways cooperate to induce DNA synthesis in response to ET-1. 
Moreover, there is evidence showing that in cerebral focal ischemia and subarachnoid hemorrhage, ET-1 is secreted in excess, not only by endothelial cells but also by astrocytes (Yamashita et al., 1994). In both pathological situations, proliferation of astrocytes was also reported. Together with our observation that ET-1 acts as a growth factor for primary astrocytes, these data strongly suggest that this neuropeptide plays a significant role in vivo in normal glial proliferation during brain development, as well as in reactive gliosis associated with brain injury or inflammation.

In conclusion, this study demonstrates that the Rho-dependent events induced by ET-1 through its G-protein-coupled receptor, in concert with adhesion to ECM proteins, constitute a pathway distinct from ERK activation, and that both pathways participate in the adhesion-dependent proliferation of astrocytes.

\section{REFERENCES}

Cazaubon SM, Couraud PO (1997) Nitric oxide and endothelin at the blood-brain barrier. In: An introduction to the blood-brain barrier (Pardridge WM, ed). Cambridge: Cambridge UP, in press.

Cazaubon SM, Ramos-Morales F, Fischer S, Schweighoffer F, Strosberg AD, Couraud PO (1994) Endothelin induces tyrosine phosphorylation and GRB2 association of SHC in astrocytes. J Biol Chem 269:24805-24809.

Cazaubon S, Parker PJ, Strosberg AD, Couraud PO (1993) Endothelins stimulate phosphorylation and activity of $\mathrm{p} 42 /$ mitogen-activated protein kinase in astrocytes. Biochem J 293:381-386.

Cobb BS, Schaller MD, Leu TH, Parsons JT (1994) Stable association of pp60src and pp59fyn with the focal adhesion-associated protein tyrosine kinase, pp125FAK. Mol Cell Biol 14:147-155.

Couraud PO, Durieu-Trautmann O, Le Nguyen P, Marin P, Glibert F, Strosberg AD (1991) Functional endothelin-1 receptors in rat astrocytoma C6. Eur J Pharmacol 206:191-198.

Craig SW, Johnson R (1996) Assembly of focal adhesions: progress, paradigms, and portents. Curr Opin Cell Biol 8:74-85.

Durieu-Trautmann O, Fédérici C, Créminon C, Foignant-Chaverot N, Roux F, Claire M, Strosberg AD, Couraud PO (1993) Nitric oxide and endothelin secretion by microvessel endothelial cells: regulation by cyclic nucleotides. J Cell Physiol 155:104-111.

Durieu-Trautmann O, Chaverot N, Cazaubon S, Strosberg AD, Couraud PO (1994) ICAM-1 activation induces tyrosine phosphorylation of the cytoskeleton-associated protein cortactin in brain microvessel endothelial cells. J Biol Chem 269:12536-12540.

Fath I, Schweighoffer F, Rey I, Multon MC, Boiziau J, Duchesne M, Tocque B (1994) Cloning of a Grb2 isoform with apoptotic properties. Science 264:971-974.

Hotchin NA, Hall A (1995) The assembly of integrin adhesion complexes requires both extracellular matrix and intracellular rho/rac GTPases. J Cell Biol 131:1857-1865.

Ladenheim R, Lacroix I, Foignant-Chaverot N, Strosberg AD, Couraud PO (1993) Endothelins stimulate c-fos and nerve growth factor expression in astrocytes and astrocytoma. J Neurochem 60:260-266.

Lazarini F, Strosberg AD, Couraud PO, Cazaubon SM (1996) Coupling of $\mathrm{ET}_{\mathrm{B}}$ endothelin receptor to mitogen-activated protein kinase stim- ulation and DNA synthesis in primary cultures of rat astrocytes. J Neurochem $66: 459-465$.

Lev S, Moreno H, Martinez R, Canoll P, Peles E, Musacchio JM, Plowman GD, Rudy B, Schlessinger J (1995) Protein tyrosine kinase PYK2 involved in $\mathrm{Ca}^{2+}$-induced regulation of ion channel and MAP kinase functions. Science 376:737-745.

Luttrell LM, Hawes BE, van Biesen T, Luttrell DK, Lansing TJ, Lefkowitz RJ (1996) Role of c-Src tyrosine kinase in G-protein-coupled receptor- and $G \beta \gamma$ subunit-mediated activation of mitogen-activated protein kinases. J Biol Chem 271:19443-19450.

MacCumber MW, Ross CA, Snyder SH (1990) Endothelin in brain: receptors, mitogenesis, and biosynthesis in glial cells. Proc Natl Acad Sci USA 87:2359-2363.

Menter DG, Herrmann JL, Nicolson GL (1995) The role of trophic factors and autocrine/paracrine growth factors in brain metastasis. Clin Exp Metastasis 13:67-88.

Morino N, Mimura T, Hamasaki K, Tobe K, Ueki K, Kikuchi K, Takehara K, Kadowaki T, Yasaki Y, Nojima Y (1995) Matrix/integrin interaction activates the mitogen-activated protein kinase, $\mathrm{p} 44^{\text {erk-1 }}$ and p42 erk-2. J Biol Chem 270:269-273.

Paulus W, Tonn JC (1995) Interactions of glioma cells and extracellular matrix. J Neurooncol 24:87-91.

Richardson A, Parsons JT (1995) Signal transduction through integrins: a central role for focal adhesion kinase? BioEssays 17:229-236.

Sadoshima J, Izumo S (1996) The heterotrimeric Gq protein-coupled angiotensin II receptor activates $\mathrm{p} 21^{\text {ras }}$ via the tyrosine kinase-ShcGrb2-SOS pathway in cardiac myocytes. EMBO J 15:775-787.

Sakurai T, Yanagisawa M, Takuwa Y, Miyazaki H, Kimura S, Goto K, Masaki T (1990) Cloning of a cDNA encoding a non-isopeptideselective subtype of the endothelin receptor. Nature 348:732-735.

Schaller MD, Parsons JT (1994) Focal adhesion kinase and associated proteins. Curr Biol 6:705-710.

Schlaepfer DD, Hanks SK, Hunter T, van der Geer P (1994) Integrinmediated signal transduction linked to Ras pathway by GRB2 binding to focal adhesion kinase. Nature 372:786-791.

Seger R, Krebs EG (1995) The MAPK signaling cascade. FASEB J 9:726-735.

Shattil SJ, Haimovich B, Cunningham M, Lipfert L, Parsons JT, Ginsberg $\mathrm{MH}$, Brugge JS (1994) Tyrosine phosphorylation of pp125 $125^{\mathrm{FAK}}$ in platelets requires coordinated signaling through integrin and agonist receptors. J Biol Chem 269:14738-14745.

Tawil N, Wilson P, Carbonetto S (1993) Integrins in point contacts mediate cell spreading: factors that regulate integrin accumulation in point contacts vs. focal contacts. J Cell Biol 120:261-271.

Wan Y, Kurosaki T, Huang X-Y (1996) Tyrosine kinases in activation of the MAP kinase cascade by G-protein-coupled receptors. J Biol Chem 380:541-544.

Wary K, Mainiero F, Isakoff S, Marcantonio E, Giancotti F (1996) The adaptor protein Shc couples a class of integrins to the control of cell cycle progression. Cell 87:733-743.

Yamashita K, Niwa M, Kataoka Y, Shigematsu K, Himeno A, Tsutsumi K, Nakano-Nakashima M, Sakurai-Yamshita Y, Shibata S, Taniyama K (1994) Microglia with an endothelin $\mathrm{ET}_{\mathrm{B}}$ receptor aggregate in rat hippocampus CA1 subfields following transient forebrain ischemia. J Neurochem 63:1042-1051. 